\title{
Article \\ Age of Diagnosis, Fidelity and Acceptability of an Early Diagnosis Clinic for Cerebral Palsy: A Single Site Implementation Study
}

\author{
Anna te Velde ${ }^{1,2}$, ${ }^{\text {, Esther Tantsis }}{ }^{3}$, Iona Novak ${ }^{1,4}$, Nadia Badawi ${ }^{1,5}$, Jane Berry ${ }^{6}$, Prue Golland ${ }^{6}$, \\ Johanna Korkalainen ${ }^{6}$, Robyn McMurdo ${ }^{6}$, Ronda Shehata ${ }^{6}$ and Catherine Morgan ${ }^{1,2}$ (D)
}

1 Cerebral Palsy Alliance Research Institute, Specialty of Child and Adolescent Health, Sydney Medical School, Faculty of Medicine and Health, The University of Sydney, Sydney, NSW 2006, Australia; inovak@cerebralpalsy.org.au (I.N.); nadia.badawi@health.nsw.gov.au (N.B.); cmorgan@cerebralpalsy.org.au (C.M.)

2 Specialty of Child and Adolescent Health, Sydney Medical School, Faculty of Medicine and Health, The University of Sydney, Sydney, NSW 2006, Australia

3 TJ Nelson Department of Neurology and Neurosurgery, Children's Hospital Westmead, Westmead, NSW 2145, Australia; esther.tantsis@health.nsw.gov.au

4 Faculty of Medicine and Health, The University of Sydney, Sydney, NSW 2006, Australia

5 Grace Centre for Newborn Intensive Care, Sydney Children's Hospital Network, The University of Sydney, Westmead, NSW 2145, Australia

6 Cerebral Palsy Alliance, Allambie Heights, NSW 2100, Australia; jberry@cerebralpalsy.org.au (J.B.); pgolland@cerebralpalsy.org.au (P.G.); jkorkalainen@cerebralpalsy.org.au (J.K.);

updates

Citation: te Velde, A.; Tantsis, E.; Novak, I.; Badawi, N.; Berry, J.; Golland, P.; Korkalainen, J.; McMurdo, R.; Shehata, R.; Morgan, C. Age of Diagnosis, Fidelity and Acceptability of an Early Diagnosis Clinic for Cerebral Palsy: A Single Site Implementation Study. Brain Sci. 2021, 11, 1074. https://doi.org/ 10.3390/brainsci11081074

Academic Editor: Brian L. Edlow

Received: 1 July 2021

Accepted: 11 August 2021

Published: 16 August 2021

Publisher's Note: MDPI stays neutral with regard to jurisdictional claims in published maps and institutional affiliations.

Copyright: (c) 2021 by the authors. Licensee MDPI, Basel, Switzerland. This article is an open access article distributed under the terms and conditions of the Creative Commons Attribution (CC BY) license (https:// creativecommons.org/licenses/by/ $4.0 /)$. rmcmurdo@cerebralpalsy.org.au (R.M.); rshehata@cerebralpalsy.org.au (R.S.)

* Correspondence: atevelde@cerebralpalsy.org.au; Tel.: +61-2-99758000

\begin{abstract}
Cerebral palsy (CP) diagnosis is historically late, at between 12 and 24 months. We aimed to determine diagnosis age, fidelity to recommended tests and acceptability to parents and referrers of an early diagnosis clinic to implement a recent evidence-based clinical guideline for the early diagnosis of CP. A prospective observational case series of infants $<12$ months with detectable risks for $\mathrm{CP}$ attending our clinic was completed with data analysed cross-sectionally. Infants had a high risk of $\mathrm{CP}$ diagnosis at a mean age of 4.4 (standard deviation [SD] 2.3) months and CP diagnosis at 8.5 [4.1] months. Of the 109 infants seen, $57 \%$ had a diagnosis of $\mathrm{CP}$ or high risk of $\mathrm{CP}$, showing high specificity to our inclusion criteria. Parent and referrer acceptability of the clinic was high. Paediatricians had the highest rate of referral (39\%) followed by allied health (31\%), primary carer $(14 \%)$ and other health workers (16\%). Fidelity to the guideline was also high. All infants referred $<5$ mths had the General Movements Assessment (GMA) and all except one had the Hammersmith Infant Neurological Examination (HINE) administered. $\mathrm{n}=92(84 \%)$ of infants seen had neuroimaging, including $n=53$ (49\%) who had magnetic resonance imaging (MRI), showing recommended tests are feasible. Referral to CP-specific interventions was at 4.7 [3.0] months, sometimes before referral to clinic. Clinicians can be confident $\mathrm{CP}$ can be diagnosed well under 12 months using recommended tools. This clinic model is acceptable to parents and referrers and supports access to CP-specific early interventions when they are likely to be most effective.
\end{abstract}

Keywords: cerebral palsy; early diagnosis; implementation science; knowledge translation; infant; early intervention

\section{Introduction}

Cerebral palsy (CP) is diagnosed between 12 and 24 months in high-income countries [1,2] and later in low- and middle-income countries, for example, 5 years in Bangladesh [3]. A recent international clinical practice guideline (hereafter termed "guideline") outlines 12 recommendations, including the best evidence-based assessments, to make an accurate and early diagnosis of CP at 3-12 months of age [1]. The 


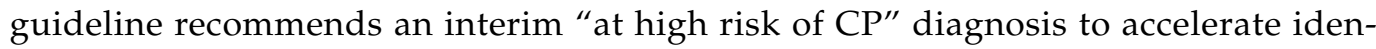
tification in mild or ambiguous cases. Early diagnosis enables access to $\mathrm{CP}$-specific evidence-based [4] interventions at an age when the infant brain has the most neuroplastic potential [5]. The guideline has been implemented in some American follow up services, lowering the age of diagnosis [6,7].

The guideline outlined two early detection pathways for the most accurate diagnosis depending on age. Infants less than 5 months old are assessed using the "newborn detectable risks" pathway, which recommends the General Movements Assessment (GMA), brain magnetic resonance imaging (MRI) and the Hammersmith Infant Neurological Examination (HINE), a standardised neurological exam [1]. Infants older than 5 months are assessed on the "infant detectable risks" pathway, in which HINE, MRI and standardised motor assessments are recommended [1], since the GMA is no longer valid. The guideline provides predictive validity for multiple standardised assessments and recommends which motor assessment to use in each age epoch; for example, the parent-reported Developmental Assessment of Young Children (DAYC) [8] is conditionally recommended for use in the infant risks group where parents are often identifying concerns. Identifying all infants with CP early requires comprehensive ascertainment because multiple causal pathways and timing of injury exist $[9,10]$. Newborn Intensive Care Unit (NICU) graduates with identifiable risks for $\mathrm{CP}$ are often followed in outpatient clinics [11] on the newborn risks pathway. However, NICU follow-up criteria vary, meaning cases are missed. Infants not meeting these criteria or those with an uncomplicated birth are typically referred later to a neurologist or paediatrician after parents or a professional identify concerns, e.g., milestone delays or asymmetries, and are usually assessed on the infant risks pathway, meaning diagnosis is made later.

Context-specific, multifaceted knowledge translation (KT) approaches should be paired with guidelines for successful implementation to close the known 15-20 year knowledge to practice gap [12]. Our group has employed country-wide knowledge translation interventions to lower the age of diagnosis. In stage one, we promoted the uptake of recommended tools (GMA and HINE) as the new standard of care by: (1) establishing a community of practice for reliability and use of the GMA; (2) educating opinion leaders; (3) seeking two Australian GMA trainers to enable local training; (4) providing financial scholarships to key opinion leaders/brokers. These stage one KT strategies improved use of the GMA (and HINE) in NICUs, as evidenced by published data on the GMA's predictive accuracy [13]. However, gaps in early diagnosis persisted, including: (1) clinician confidence to make an early diagnosis; and (2) absence of diagnostic services for infants not meeting NICU follow-up criteria or with no known risks for CP at birth or with no neurology services available. In a stage two response, we established a specialist early diagnosis clinic, hereafter termed "clinic", to expedite diagnosis in the community. This paper reports on the impact of the clinic in lowering the age of diagnosis in both NICU and non-NICU graduates.

The primary aim of this paper was (1) to determine age of diagnosis of infants attending our clinic. Secondary aims were to determine: (2) if the infant risks group are diagnosed later than the newborn risks group; (3) if the right infants were targeted for the diagnostic process; (4) if guideline fidelity could be maintained [1]; and (5) acceptability of the clinic by parents and referrers. We hypothesised: (1) infants could be diagnosed under 12 months by implementing guideline recommendations underpinned by a multifaceted KT strategy; (2) the infant risks group would be diagnosed later than the newborn risks group; (3) $>50 \%$ of infants referred would have $\mathrm{CP}$ or high risk of $\mathrm{CP}$ based on clinic eligibility criteria; (4) fidelity to evidence pathways in the guideline [1] could be maintained; and (5) parents and referrers would find the clinic acceptable. 


\section{Materials and Methods}

\subsection{Design}

A prospective observational case series was conducted. Data for the first 30 months of clinic operation, from March 2018, were analysed cross-sectionally. No sample size was calculated, with all eligible infants included. Results were reported as per the Standards for Reporting Implementation Studies statement [14] (Supplementary Table S1).

\subsection{Implementation Strategy}

We applied a multifaceted knowledge translation package to our newly established diagnostic clinic to lower the age of diagnosis in the community. The clinic structure is outlined in Table 1. Eight evidence-based KT strategies were selected as solutions to overcome barriers to guideline implementation [15,16], including: (1) targeting practitioner attitudes regarding early diagnosis [17]; (2) guideline awareness [18]; (3) knowledge brokers' use of early diagnosis evidence to inform policymakers within both collaborating institutions; (4) use of opinion leaders [19]; (5) industry experts mentoring clinic staff [20]; (6) medical and parent self-referral to clinic (parent-mediated KT strategy) [21]; (7) leveraging on a research active culture, including employing research clinicians [22]; and (8) Neurologist employed as medical lead [23]. KT strategy planning utilised the Knowledge-to-Action process [24] (Figure 1). Supplementary Table S2 details all identified barriers, facilitators and supporting evidence for KT strategies selected.

Table 1. Description of clinic based on Template for Intervention Description and Replication (TIDieR [25]).

\begin{tabular}{|c|c|}
\hline Name & Cerebral Palsy Alliance and NSW Health Early Diagnosis Clinic \\
\hline Why & $\begin{array}{l}\text { Clinic purposes: } \\
\text { Decrease the age of diagnosis of } \mathrm{CP} \\
\text { Referral to CP-specific infant early interventions, parent wellbeing } \\
\text { supports and funding } \\
\text { Decrease motor severity of CP through early monitoring of associated } \\
\text { impairments }\end{array}$ \\
\hline \multirow[b]{2}{*}{ What } & $\begin{array}{l}\text { Materials: } \\
\text { Comfortable room with one-way viewing window and sound for } \\
\text { observation } \\
\text { Assessment tools: bench, weight and length measures, reflex hammer, } \\
\text { paper tape measure, ophthalmoscope, blood pressure kit, infant toys, stairs, } \\
\text { high chair and tray, adjustable bench } \\
\text { Assessment kits: BSID-III, HAI, HINE and PDMS-2 }\end{array}$ \\
\hline & $\begin{array}{l}\text { Procedures: } \\
\text { Parent or health worker referral } \\
\text { Intake officer collects infant details and relevant assessment findings } \\
\text { Neurologist and intake officer assess eligibility } \\
\text { A valid medical referral required for Medicare billing, the Australian } \\
\text { universal health insurance scheme } \\
\text { Infant, family and multidisciplinary team attend initial appointment } \\
\text { Ongoing appointments with the purpose of diagnostic process and/or } \\
\text { developmental surveillance to } 2 \text { years of age }\end{array}$ \\
\hline Who provided & $\begin{array}{l}\text { Experienced multidisciplinary team, including: neurologist, } \\
\text { physiotherapist, occupational therapist, speech pathologist, social worker, } \\
\text { intake officer, administration assistant and manager }\end{array}$ \\
\hline How & $\begin{array}{l}\text { One day / week with } 4 \times 90 \text { min appointments/day } \\
\text { Assessments, scoring, feedback to parents, liaison with other services and } \\
\text { reporting completed on clinic day }\end{array}$ \\
\hline Where & $\begin{array}{l}\text { South Western Sydney, NSW, Australia. The region with highest } \\
\text { socioeconomic disadvantage in Sydney. }\end{array}$ \\
\hline
\end{tabular}


Table 1. Cont.

\begin{tabular}{cl}
\hline Name & \multicolumn{1}{c}{ Cerebral Palsy Alliance and NSW Health Early Diagnosis Clinic } \\
\hline $\begin{array}{c}\text { When and how } \\
\text { much }\end{array}$ & $\begin{array}{l}\text { Initial appointment occurs as soon as possible after referral } \\
\text { Ongoing appointments at 3, 6,9,12,18 and 24 months corrected age as } \\
\text { appropriate }\end{array}$ \\
\hline \multirow{2}{*}{ Tailoring } & $\begin{array}{l}\text { Physical space is tailored as per best practice guidelines for communicating } \\
\text { diagnoses and is a quiet, private and inviting room with enough space for } \\
\text { staff, assessment and for both parents / support person to be present for the } \\
\text { diagnosis }\end{array}$ \\
\hline \multirow{3}{*}{ Modifications } & $\begin{array}{l}\text { During COVID-19 pandemic restrictions (March to June 2020), the clinic } \\
\text { operated as a telehealth service and included the following modifications: } \\
\text { No initial appointments } \\
\text { No CP diagnoses made via telehealth } \\
\text { HINE not completed via telehealth }\end{array}$ \\
\hline
\end{tabular}

Abbreviation: BSID-III, Bayley Scales of Infant and Toddler Development 3rd Version; CP, cerebral palsy; HAI, Hand Assessment for Infants; HINE, Hammersmith Infant Neurological Examination; NSW, New South Wales; PDMS-2, Peabody Developmental Motor Scales-2.

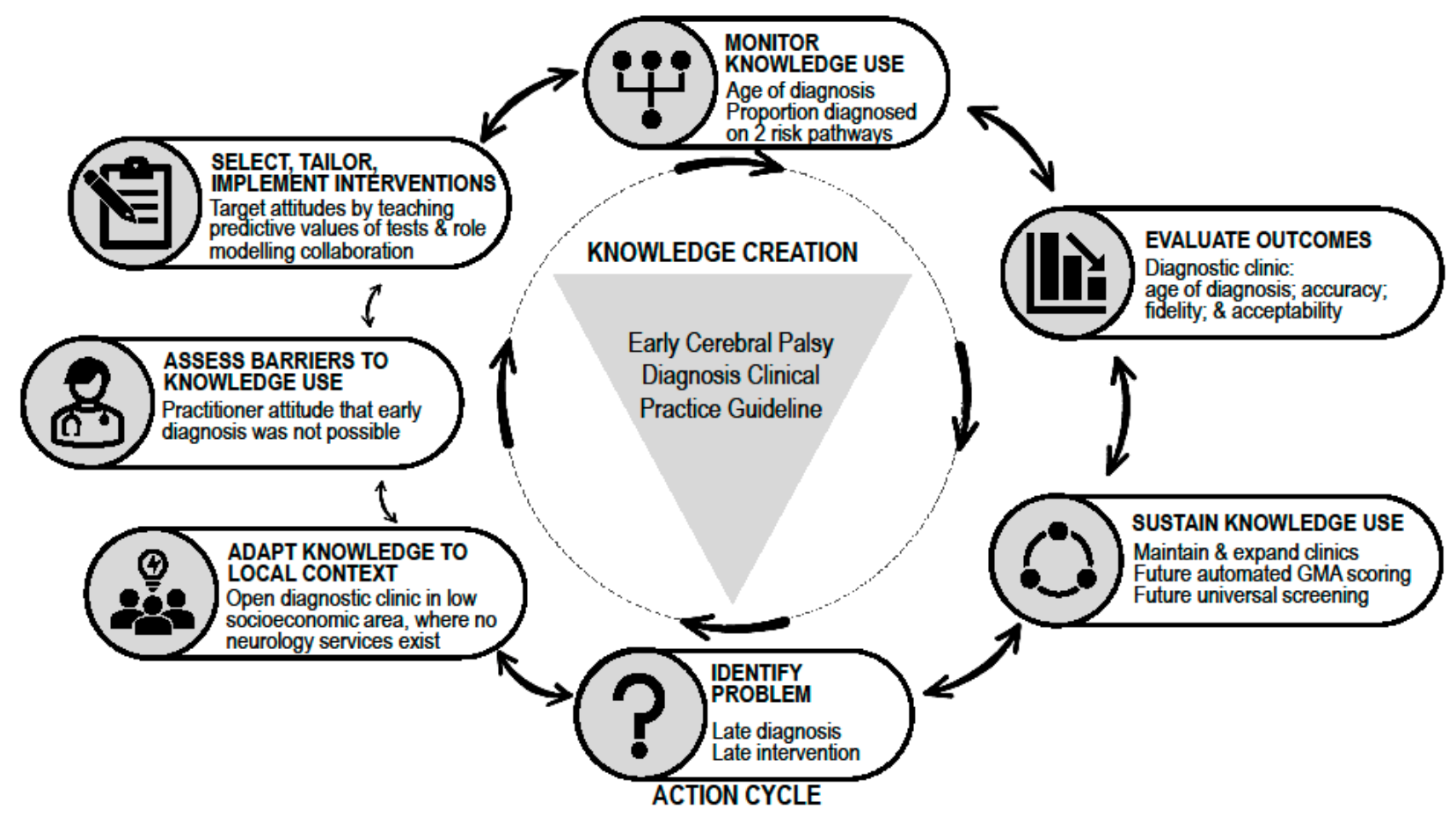

Figure 1. Knowledge translation strategy example using Knowledge-to-Action cycle [25]. Abbreviation: GMA, General Movements Assessment.

\subsection{Implementation Site}

Referrals to clinic were primarily from one state, New South Wales, with a population of 8.16 million and 315,000 births annually [26], and targeted a region with a growing population and high level of socioeconomic disadvantage, due to the socioeconomic gradient associated with disability [27].

\subsection{Clinic Eligibility Criteria}

Eligibility criteria were designed to capture any infant with risks for $\mathrm{CP}$ but not yet diagnosed. These included:

1. $<12$ months corrected age; and

2. No current neurologist; and

3. Medical referral; and 
4. Signs of motor dysfunction, for example: Trajectory of cramped synchronised general movements at writhing age, absent fidgety general movements at fidgety age [28]; or

a. Below average scores on standardised motor assessment; or

b. Specific motor milestones delay, e.g., hand asymmetry $>4$ months, not sitting $>9$ months [29] and either:

5. Clinical history with risks for CP $[1,30,31]$; or

6. Neuroimaging indicating motor impairment [1].

\subsection{Outcomes}

\subsubsection{Primary Outcomes}

Age of diagnosis (guideline recommendation 1.0) was analysed at three "stages" in the diagnosis process: (1) age any service suspected CP, as per the guideline criteria; (2) age when $\mathrm{CP}$ or high risk of $\mathrm{CP}$ diagnosis given at clinic; and (3) age $\mathrm{CP}$ confirmed. Diagnostic outcomes included (1) CP [32]; (2) high risk of CP [1]; (3) no CP, other diagnosis; and (4) no $\mathrm{CP}$, no apparent concerns.

\subsubsection{Secondary Outcomes}

Fidelity to guideline recommendations was measured using the proportion of infants with (1) diagnostic tests completed (recommendations 2.0-6.2); (2) referral to CP-specific early intervention, disability-specific funding and $\mathrm{CP}$-specific medical services (recommendation 10.0); and (3) screened for associated impairments (recommendation 11.0).

Acceptability of parents and referrers was measured using (1) referrer profiles; (2) proportion of appointments attended; and (3) Measure of Processes of Care (MPOC20) questionnaires [33], which measure family centeredness of a service on five scales from 0 (not at all) to 7 (to a very great extent). Questionnaires were completed by anonymous mail survey.

\subsection{Statistical Analysis}

Outcomes were analysed using descriptive statistics. All analyses were completed in Excel ${ }^{\circledR}$ 2019. Independent $t$-test was used to analyse between group differences for age of diagnosis.

\section{Results}

\subsection{Eligibility, Age of Diagnosis and Diagnosis Outcomes}

Eligibility, age of referral: Infant demographics and risk factors are reported in Table 2. Of $\mathrm{n}=148$ infants referred, $\mathrm{n}=109$ had attended, $\mathrm{n}=12$ were waiting on an appointment, $n=2$ declined or not contactable and $n=25$ were ineligible. The $n=109$ infants seen were referred at mean age 5.7 (standard deviation [SD] 3.1) months and first seen at 7.2 [3.3] months.

Table 2. Infant demographics and risk factors for cerebral palsy.

\begin{tabular}{lcc}
\hline & $\begin{array}{c}\text { All Infants, } \\
\mathbf{n}(\mathbf{\%}) \\
\mathbf{n = 1 0 9}\end{array}$ & $\begin{array}{c}\mathbf{C P}, \\
\mathbf{N}(\mathbf{\%}) \\
\mathbf{n}=\mathbf{4 8}\end{array}$ \\
\hline $\begin{array}{l}\text { Demographics } \\
\text { Sex }\end{array}$ & & \\
$\quad$ Female & & \\
$\quad$ Male & $46(42)$ & $20(42)$ \\
Prematurity & $63(58)$ & $28(58)$ \\
$\quad$ Extreme preterm (<28 weeks) & $11(10)$ & $5(10)$ \\
$\quad$ Very preterm (28-32 weeks) & $29(27)$ & $13(27)$ \\
$\quad$ Moderate to late preterm (32-<37 weeks) & $14(13)$ & $8(17)$ \\
$\quad$ Term >37 weeks & $55(51)$ & $22(46)$ \\
\hline
\end{tabular}


Table 2. Cont.

\begin{tabular}{|c|c|c|}
\hline & $\begin{array}{c}\text { All Infants, } \\
\text { n (\%) } \\
\text { n = } 109\end{array}$ & $\begin{array}{c}\mathrm{CP} \\
\mathrm{N}(\%) \\
\mathrm{n}=48\end{array}$ \\
\hline \multicolumn{3}{|l|}{ Birthweight } \\
\hline$<10$ th percentile for gestational age [34] & $23(21)$ & $12(25)$ \\
\hline \multicolumn{3}{|l|}{ Preconceptual risk factors [31] } \\
\hline Maternal thyroid disease (hypo and hyperthyroidism) & $10(9)$ & $5(10)$ \\
\hline Sibling with disability & $16(15)$ & $3(6)$ \\
\hline \multicolumn{3}{|l|}{ Antenatal risk factors [31] } \\
\hline In vitro fertilisation (IVF) conception & $15(14)$ & $4(8)$ \\
\hline \multicolumn{3}{|l|}{ Congenital anomalies a } \\
\hline Cerebral ${ }^{b}$ & $15(14)$ & $8(17)$ \\
\hline Cardiac & $10(9)$ & $9(19)$ \\
\hline Musculoskeletal & $17(16)$ & $5(10)$ \\
\hline Genitourinary & $3(3)$ & $2(4)$ \\
\hline Digestive system & $11(10)$ & $4(8)$ \\
\hline At least 1 congenital anomaly ${ }^{c}$ & $42(39)$ & $20(42)$ \\
\hline Chorioamnionitis & $7(6)$ & $2(4)$ \\
\hline Preeclampsia & $15(14)$ & $7(15)$ \\
\hline Intrauterine growth restriction & $21(19)$ & $11(23)$ \\
\hline Maternal infection during pregnancy (confirmed) & $23(21)$ & $10(21)$ \\
\hline Multiple birth & $12(11)$ & $6(13)$ \\
\hline \multicolumn{3}{|l|}{ Intrapartum risk factors [31] } \\
\hline Confirmed hypoxic ischemic encephalopathy & $11(10)$ & $8(17)$ \\
\hline Meconium aspiration & $2(2)$ & $0(0)$ \\
\hline Emergency caesarean section & $53(49)$ & $30(63)$ \\
\hline $\begin{array}{l}\text { Other instrumental delivery (non-emergency caesarean section, } \\
\text { other instrumental delivery) }\end{array}$ & $12(11)$ & $5(10)$ \\
\hline \multicolumn{3}{|l|}{ Neonatal and post neonatal risk factors [31] } \\
\hline Presence of neonatal seizures & $15(14)$ & $9(19)$ \\
\hline Respiratory Distress Syndrome & $61(56)$ & $28(58)$ \\
\hline Neonate hypoglycaemia & $26(24)$ & $12(48)$ \\
\hline Perinatal infection (up to 1 month of age) & $9(8)$ & $3(6)$ \\
\hline Post neonatal infection (after 1 month of age) & $7(6)$ & $3(6)$ \\
\hline Jaundice & $46(42)$ & $23(48)$ \\
\hline Perinatal stroke (up to 1 month of age) & $9(8)$ & $7(15)$ \\
\hline Post neonatal stroke (after 1 month of age) & $3(3)$ & $3(6)$ \\
\hline
\end{tabular}

Age of diagnosis (Table 3): Of the $\mathrm{n}=109$ infants assessed, the mean age any referring service suspected $\mathrm{CP}$ was 4.4 [2.3] months. $\mathrm{CP}$ diagnosis was confirmed in clinic at 8.5 [4.1] months. The newborn risk group was identified earlier for suspected $\mathrm{CP}$ (3.6 [1.1] months) than the infant detectable risks group 9.0 [2.7] months $(t=-5.25$, $p=0.00$ ), but no difference was found at age of CP diagnosis (newborn detectable risks group 8.1 [4.2] months; infant detectable risks group 10.6 [1.9] months, $t=-2.12$, $p=0.05)$.

Diagnostic outcome (Table 4): A CP or high risk of CP diagnosis was given to $57 \%$ of infants, accounting for $19 \%$ of infants estimated to be diagnosed with CP in New South Wales during the study period. One infant $(1 \%)$ had CP diagnosis, which was later revoked and for analysis is included in the no $\mathrm{CP}$, other diagnosis group. 
Table 3. Age of diagnosis.

\begin{tabular}{|c|c|c|c|c|c|c|c|c|c|}
\hline \multirow{3}{*}{ Diagnosis Process Stage } & \multirow{2}{*}{\multicolumn{3}{|c|}{$\begin{array}{c}\begin{array}{c}\text { Newborn Detectable } \\
\text { Risks } \\
(\mathrm{n}=76)^{a}\end{array} \\
\text { Age, Months }\end{array}$}} & \multicolumn{3}{|c|}{$\begin{array}{c}\text { Infant Detectable } \\
\text { Risks } \\
(\mathrm{n}=33)\end{array}$} & \multicolumn{3}{|c|}{$\begin{array}{l}\text { All Infants } \\
(n=109)\end{array}$} \\
\hline & & & & \multirow[b]{2}{*}{$\mathbf{n}$} & \multicolumn{2}{|c|}{ Age, Months } & \multirow[b]{2}{*}{$\mathbf{n}$} & \multicolumn{2}{|c|}{ Age, Months } \\
\hline & $\mathbf{n}$ & $\begin{array}{c}\text { Mean } \\
\text { (SD) }\end{array}$ & $\begin{array}{l}\text { Median } \\
\text { (Range) }\end{array}$ & & $\begin{array}{l}\text { Mean } \\
\text { (SD) }\end{array}$ & $\begin{array}{l}\text { Median } \\
\text { (Range) }\end{array}$ & & $\begin{array}{l}\text { Mean } \\
\text { (SD) }\end{array}$ & $\begin{array}{l}\text { Median } \\
\text { (Range) }\end{array}$ \\
\hline $\begin{array}{l}\text { Any clinical service } \\
\text { suspected CP }\end{array}$ & 53 & $\begin{array}{l}3.6 \\
(1.1)\end{array}$ & $4(0-7)$ & 9 & $\begin{array}{c}9.0 \\
(2.7)\end{array}$ & $\begin{array}{c}10 \\
(5-12)\end{array}$ & 62 & $4.4(2.3)$ & $\begin{array}{c}4 \\
(0-12)\end{array}$ \\
\hline $\begin{array}{c}\mathrm{CP} \text { or high risk of } \mathrm{CP} \\
\text { diagnosis at first clinic } \\
\text { appointment }\end{array}$ & 53 & $\begin{array}{l}6.0 \\
(2.6)\end{array}$ & $\begin{array}{c}6 \\
(0-13)\end{array}$ & 9 & $\begin{array}{c}9.8 \\
(2.7)\end{array}$ & $\begin{array}{c}10 \\
(5-13)\end{array}$ & 62 & $\begin{array}{c}6.6 \\
(3.0)\end{array}$ & $\begin{array}{c}6 \\
(0-13)\end{array}$ \\
\hline CP confirmed & 40 & $\begin{array}{c}8.1 \\
(4.2)\end{array}$ & $\begin{array}{c}7 \\
(5-19)\end{array}$ & 8 & $\begin{array}{l}10.6 \\
(1.9)\end{array}$ & $\begin{array}{c}10.5 \\
(8-13)\end{array}$ & 48 & $\begin{array}{c}8.5 \\
(4.1)\end{array}$ & $\begin{array}{c}8 \\
(2-19)\end{array}$ \\
\hline
\end{tabular}

Abbreviations: $\mathrm{CP}$, cerebral palsy; $\mathrm{n}=$ number; SD, standard deviation. ${ }^{\mathrm{a}} \mathrm{n}=6$ infants in the newborn detectable risks group did not have identified risks requiring follow up at birth but were assessed in time to have the General Movements Assessment video completed.

Table 4. Diagnostic Outcome.

\begin{tabular}{cccc}
\hline & $\begin{array}{c}\text { Newborn Detectable } \\
\text { Risks, } \mathbf{n}(\mathbf{\%}) \\
\mathbf{n}=\mathbf{7 6}\end{array}$ & $\begin{array}{c}\text { Infant Detectable } \\
\text { Risks, } \mathbf{n}(\mathbf{\%}) \mathbf{n}=\mathbf{3 3}\end{array}$ & $\begin{array}{c}\text { All Infants, } \mathbf{n}(\%) \\
\mathbf{n}=\mathbf{1 0 9}\end{array}$ \\
\hline CP & $40(53)$ & $8(24)$ & $48(44)$ \\
High risk of CP & $13(17)$ & $1(3)$ & $14(13)$ \\
No CP, other diagnosis a,b & $14(18)$ & $9(27)$ & $23(21)$ \\
No CP, no concerns & $8(11)$ & $14(42)$ & $22(20)$ \\
Lost to follow up & $1(1)$ & $1(3)$ & $2(2)$ \\
\hline
\end{tabular}

Abbreviations: $\mathrm{CP}$, cerebral palsy; $\mathrm{n}=$ number. ${ }^{\text {a }}$ Other diagnoses suspected or confirmed: Autism Spectrum Disorder; congenital hypothyroidism; external hydrocephalus; global developmental delay $(n=3)$; language delay; meningoencephalitis; motor delay; persistent toe walking; plagiocephaly and torticollis; primary connective tissue disorders; genetic disorders not associated with $\mathrm{CP} .{ }^{\mathrm{b}}$ Includes $\mathrm{n}=1$ infant with $\mathrm{CP}$ diagnosis revoked.

\subsection{Fidelity to International Clinical Guideline}

\subsubsection{Diagnostic Tests}

Proportions of tests completed are reported in Table 5. All infants identified $<5$ months were assessed with GMA. All infants, except one, had HINE completed. Neuroimaging: Of $n=109$ infants seen, $84 \%$ had neuroimaging prior to clinic. $n=43(39 \%)$ were referred for MRI from clinic. Combination of GMA, neuroimaging and HINE: In total, $\mathrm{n}=19$ infants had triangulating findings predictive of $\mathrm{CP}$ (i.e., absent fidgety on GMA; neuroimaging predictive of motor impairment and HINE below reported CP cut scores [35]), of whom $\mathrm{n}=17$ had a diagnosis of $\mathrm{CP} ; \mathrm{n}=2$ had global developmental delay or attention problems. Genetic testing: While not an explicit guideline recommendation, some infants were sent for genetic screening if $\mathrm{CP}$ aetiology was unclear, e.g., infants with normal or non-specific MRI findings or dysmorphic features.

\subsubsection{CP Classification}

(Recommendations 8.0-9.0): Predominant motor type: Of the 48 infants with CP, 73\% were classified as spastic, $15 \%$ dyskinetic, $0 \%$ ataxic, $2 \%$ hypotonic predominant motor type as per the Australian Cerebral Palsy Register [36] and 10\% were too young to classify accurately. Topography: Of the $\mathrm{n}=38$ infants with spastic motor type, $47 \%$ had hemiplegia, $21 \%$ diplegia and 32\% quadriplegia. Motor Severity: We used the Gross Motor Function Classification System (GMFCS) [37] to classify infants with CP $(n=48)$ : Level I $(50 \%)$, level II $(25 \%)$, level III $(0 \%)$, level IV $(8 \%)$, and level V $(8 \%)$ with $8 \%$ too young to classify as $<12$ months. Topography and motor severity data reflect Australian population register trends [36], suggesting a representative sample with external validity. 
Table 5. Cerebral palsy-specific diagnostic tests completed ${ }^{\mathrm{a}}$.

\begin{tabular}{|c|c|c|c|c|c|c|}
\hline & \multicolumn{3}{|c|}{ All Infants } & \multicolumn{3}{|c|}{$\mathbf{C P}$} \\
\hline & $\begin{array}{c}\text { Newborn } \\
\text { Detectable Risks, n (\%) } \\
\text { n }=76\end{array}$ & $\begin{array}{c}\text { Infant Detectable } \\
\text { Risks, n (\%) } \\
\text { n }=33\end{array}$ & $\begin{array}{c}\text { Total, n (\%) } \\
\text { n = } 109\end{array}$ & $\begin{array}{c}\text { Newborn } \\
\text { Detectable Risks, } \\
\text { n (\%) } \\
n=40\end{array}$ & $\begin{array}{c}\text { Infant Detectable } \\
\text { Risks, n (\%) } \\
\text { n = 8 }\end{array}$ & $\begin{array}{c}\text { Total, n (\%) } \\
\mathrm{n}=48\end{array}$ \\
\hline \multicolumn{7}{|c|}{ General Movements Assessment Writhing Period ( ${ }^{a}$ recommendation 3.1) } \\
\hline Administered externally prior to clinic & $42(55)$ & NA & $42(39)$ & $21(53)$ & NA & $21(44)$ \\
\hline \multicolumn{7}{|c|}{ General Movements Assessment Fidgety Period ( ${ }^{a}$ recommendation 3.1) } \\
\hline Administered at clinic & $6(8)$ & NA & $6(6)$ & $2(5)$ & NA & $2(4)$ \\
\hline No GMA, infant too old & $0(0)$ & NA & $33(30)$ & $0(0)$ & $8(100)$ & $8(17)$ \\
\hline \multicolumn{7}{|c|}{ Neuroimaging $\left({ }^{\text {a }}\right.$ recommendation 4.2$)$} \\
\hline Neuroimaging conducted prior to clinic & & & & & & \\
\hline CUS only & $25(33)$ & $14(42)$ & $39(36)$ & $11(28)$ & $3(38)$ & $14(29)$ \\
\hline MRI only & $29(38)$ & $5(15)$ & $34(31)$ & $20(50)$ & $2(25)$ & $22(46)$ \\
\hline CUS + MRI & $19(25)$ & $0(0)$ & $19(17)$ & $9(23)$ & $0(0)$ & $9(19)$ \\
\hline No neuroimaging prior to clinic & $3(4)$ & $14(42)$ & $17(16)$ & 0 & $3(38)$ & $3(6)$ \\
\hline First administration at clinic & $30(40)$ & $22(67)$ & $51(47)$ & $18(45)$ & $6(75)$ & $24(50)$ \\
\hline HINE not administered & $1(1)$ & $0(0)$ & $1(1)$ & $1(3)$ & $0(0)$ & $1(2)$ \\
\hline
\end{tabular}

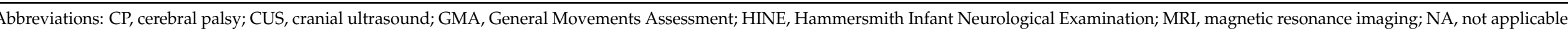

a Assessments based on recommendations 2.0 and 3.0-7.1 of the international clinical guideline for early and accurate detection of cerebral palsy [1]. 
3.2.3. Referral to CP-Specific Early Intervention Funding and Medical Services (Recommendation 10.0)

For infants with CP, 98\% were referred to CP-specific early interventions, with services first accessed at 4.7 [3.0] months. All were referred for funding through the National Disability Insurance Scheme at 4.0 [4.0] months. Seventy-seven percent were referred to CPspecific medical rehabilitation services for management of tone, pain and hip surveillance at 12.1 [5.1] months.

\subsubsection{Associated Impairment Screening (Recommendation 11.0)}

The following concerns were identified and referrals were made for infants with CP: vision (46\%); hearing (17\%); communication delay (69\%), feeding concern $(40 \%)$. Risk of seizures discussion was documented in $79 \%$ of infants with CP; $23 \%$ of infants had seizure management in place; $13 \%$ had seizures identified through clinic; $52 \%$ required no seizure management and $13 \%$ did not have seizure status documented.

\subsubsection{Parent Wellbeing (Recommendation 1.0)}

This was discussed for every family; support options were documented in $85 \%$ of cases.

\subsection{Acceptability}

Acceptability by parents and referrers was high. $n=2(2 \%)$ of the 123 eligible infants declined an appointment or were non-contactable. Paediatricians had highest rate of referral (39\%) followed by Physiotherapists (24\%), primary care giver (14\%), Neonatologists (7\%), Occupational Therapists (7\%), Neurologists (4\%), Social Workers (2\%), Nurses (1\%), General Practitioners (1\%) and other health workers (1\%). Sixty percent of referred infants were also captured in NICU follow up. Parents rated the clinic on the MPOC-20, from 23 responses (21\% response rate), on respectful and supportive care (mean score 6.4 [0.6]); coordinated and comprehensive care (6.4 [0.7]); providing specific information about child (5.6 [1.6]); enabling and partnership (5.9 [1.4]); and providing general information (4.8 [1.7]). No harms or unintended effects were observed.

\section{Discussion}

Our aim was to determine the age of CP diagnosis by implementing the international clinical guideline [1] in a multifaceted evidence-based knowledge translation strategy packaged as an early diagnosis clinic. We found high risk of CP was identified at 4.4 months, early intervention started by 4.7 months and CP diagnosis was made at 8.5 months on average. Infants were referred at 5.7 months, i.e., in some cases after CP was suspected and intervention commenced, showing a delay from identification to referral. These data

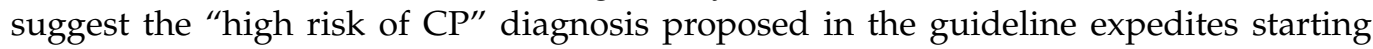
interventions in the right infants at an early age. Infants with $\mathrm{CP}$ on the newborn risks pathway were mainly accurately identified as high risk of $\mathrm{CP}$, but not given a $\mathrm{CP}$ diagnosis, by community providers prior to referral to this clinic. This suggests barriers still exist, for example, confidence to make and communicate an early diagnosis. Overall, we found $\mathrm{CP}$ could be diagnosed well under 12 months. This is lower than previously reported, for example, 18.9 months ( \pm 12.8 months) in Canada [2]. Diagnosis age from this clinic is comparable to some clinical service models used to implement the guideline [7] and even earlier than other models [6], suggesting the eligibility criteria and knowledge translation strategies that we used were effective for guideline implementation. This is particularly important given the age of diagnosis of CP has not changed over the past three decades [36].

Commencing CP-specific early interventions in the first few months of life is likely to be key to decreasing the severity of impairments, as neuroplasticity is enhanced in the young brain. Child-active motor learning interventions to harness neuroplasticity in infants with CP are underway globally [4]. However, based on our results, a proportion of infants with CP still experience up to 5 months delay accessing intervention because they did not fit the "newborn detectable risk" profile. The infant detectable risk group was a smaller 
proportion of our cohort and was less likely to receive a diagnosis of $\mathrm{CP}$, suggesting an under representation of children with infant detectable risks in our clinic, which indicates ongoing KT issues at a community level.

The proportion of infants in our clinic diagnosed with $\mathrm{CP}$ or high risk of $\mathrm{CP}(57 \%)$ was higher than a recently reported neurodevelopment follow up clinic $(22 \% \mathrm{CP}$ or high risk of $\mathrm{CP}$ [38]) and met our hypothesis. This difference probably reflects the specificity of our eligibility criteria. There is considerable expertise in administering GMA and HINE in Australia, particularly in NICU follow up clinics $[13,39]$ due to previous knowledge translation work. In our cohort, over $90 \%$ of infants had GMA videos and over $50 \%$ had HINE completed prior to the early diagnosis clinic appointment in NICU follow up or community services.

We were able to maintain fidelity to each of the guideline recommendations. All infants within the age for GMA had a scorable video and all except one infant had the HINE administered on at least one occasion. Access to term equivalent age (TEA) MRI was a barrier to an early or accurate diagnosis for some infants. While almost $50 \%$ of infants had an MRI prior to their initial appointment, not all were at term equivalent age as recommended $[1,40,41]$. Although $C P$ is a clinical diagnosis, and $10-15 \%$ of children with CP have seemingly normal findings on MRI [42-44], MRI has the second highest predictive validity for detecting CP after GMA. Barriers to TEA MRI include accessibility and neonate medical stability. In addition, major lesions predictive of $\mathrm{CP}$, e.g., cystic periventricular leukomalacia [40], can be detected on CUS in preterm infants; however, CUS has lower sensitivity for detecting milder motor injuries [41]. TEA MRI would support early diagnosis and earlier classification of motor severity, type and topography of $\mathrm{CP}$ and associated impairments, e.g., vision impairment. Infants with $\mathrm{CP}$ in this cohort with triangulating findings on GMA, HINE and MRI all predictive of $\mathrm{CP}$ corroborated the report of the high pooled accuracy of these three tests [45]. In practice, we found use of GMA, HINE and MRI was feasible as was screening for associated impairments. The Peabody Developmental Motor Scales (PDMS-2) [46] were used as a standardised motor assessment rather than the DAYC [8]. PDMS-2 is more detailed than the DAYC, and PDMS-2 was not specifically recommended in the guideline to lower assessor burden but has moderate predictive validity [1]. The Hand Assessment of Infants (HAI) [47] is also used if unilateral $\mathrm{CP}$ is suspected. The HAI is a newer tool, where the psychometric data became available after guideline publication.

Parents want to know at the earliest age if their child has CP [48,49]. When a diagnosis is communicated appropriately, parents are more likely to take an active role in their child's

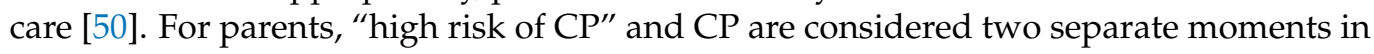

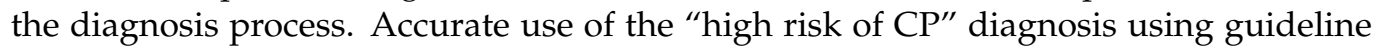
criteria does and should allow access to intensive interventions while further diagnostic assessment occurs. However, a CP diagnosis should still be made at the earliest possible age, giving clarity to parents. Guideline recommendations are designed for both early and accurate diagnosis. Diagnosis accuracy ensures effective distribution of health resources. In our study, $<1 \%$ of infants had a CP diagnosis revoked compared to $2.9 \%$ recently reported in Canada [51]. Analysis of larger numbers using this clinic model will determine if this low rate is maintained.

Parents overwhelmingly found the clinic acceptable. Parents who found the service online made up $14 \%$ of referrals. Direct parent referral is logical, particularly for the infant detectable risks group, because parents suspect $\mathrm{CP}$ before a diagnosis [52] and are the most vigilant observers of their child's development. Parents rated the clinic as moderate or high on measures of family centeredness on the MPOC-20, with scores slightly higher than children with physical disability in Iceland [53]. "Providing general information" at clinic appointments was identified as an area for improvement. In response, the Cerebral Palsy Alliance published the Early Childhood Intervention Guide [54], which is now given to parents after a diagnosis and is available online. 
Future Directions: Universal GMA testing is likely to be most impactful for early detection of $\mathrm{CP}$ for all infants before 6 months because GMA has the best predictive validity for $\mathrm{CP}$, and automated technologies to assess GMA accurately, ethically and economically are progressing [55]. An Australian precedent exists in universal newborn hearing screening, leading to earlier hearing interventions with improved hearing and language outcomes [56,57]. Human services will be required to wrap around universal GMA screening to make timely diagnoses and ensure access to early interventions. KT strategies to increase the confidence of community providers to make and communicate a diagnosis could further decrease the age of diagnosis. The proportion of infants captured in this clinic shows the scalability of the model and this clinic will be replicated in Australia. Testing of the model in various settings with site-specific barrier analysis will provide more confidence in the model and make it broadly applicable.

Limitations: This study was a single site, prospective observational case series with no comparison group available to determine the impact of the clinic compared to other models on age of diagnosis. The study design, the specificity of the location and the tailored KT strategies are limitations for the application of the model in other socioeconomic contexts. It is too early to say if this clinic model can decrease the age of diagnosis on a population level, with our inclusion criteria making this clinic more likely to diagnose CP. The Knowledge Translation of Early Cerebral Palsy study is underway in Australia testing the effectiveness of implementing recommended diagnostic tools; we await the results.

This clinic was located in a high-income country metropolitan location. Families travelled from regional locations to this clinic, showing parents want this service. Implementation strategies for remote regions and low- and middle-income country contexts are needed to ensure equal access to diagnostic services.

\section{Conclusions}

Clinicians can be confident that cerebral palsy can be diagnosed well under 12 months using the tools outlined in the guideline within the real world. Parents and referrers found our clinic model acceptable, providing another guideline implementation strategy. Infants with $\mathrm{CP}$ with a seemingly normal birth history are still diagnosed later and may be missing the window for early intervention under 6 months when neuroplasticity is highest.

Supplementary Materials: The following are available online at https://www.mdpi.com/article/10 .3390 / brainsci11081074/s1, Table S1: Standards for Reporting Implementation Studies: the StaRI checklist, Table S2: Barriers, Facilitators with Corresponding Knowledge Translation Strategies of Early Diagnosis Clinic.

Author Contributions: Conceptualization, A.t.V., I.N., N.B. and C.M.; Data curation, A.t.V., E.T. and C.M.; Formal analysis, A.t.V. and C.M.; Investigation, A.t.V., E.T., I.N., J.B., P.G., J.K., R.M., R.S. and C.M.; Methodology, A.t.V., I.N., N.B. and C.M.; Project administration, A.t.V., E.T. and P.G.; Supervision, I.N., N.B. and C.M.; Visualization, A.t.V., I.N. and C.M.; Writing-original draft, A.t.V.; Writing-review and editing, A.t.V., E.T., N.B. and C.M. All authors have read and agreed to the published version of the manuscript.

Funding: This research received no external funding.

Institutional Review Board Statement: The study was approved by the Sydney Children's Hospitals Network Human Research Ethics Committee (Reference 2021/ETH00680, date of approval 1 June 2021).

Informed Consent Statement: A combination of informed and waiver of consent was applied to patients not currently in clinic service as per ethical approval.

Conflicts of Interest: The authors declare no conflict of interest. 


\section{References}

1. Novak, I.; Morgan, C.; Adde, L.; Blackman, J.; Boyd, R.N.; Brunstrom-Hernandez, J.; Cioni, G.; Damiano, D.; Darrah, J.; Eliasson, A.C.; et al. Early, Accurate Diagnosis and Early Intervention in Cerebral Palsy: Advances in Diagnosis and Treatment. JAMA Pediatr. 2017, 171, 897-907. [CrossRef]

2. Boychuck, Z.; Andersen, J.; Fehlings, D.; Kirton, A.; Oskoui, M.; Shevell, M.; Majnemer, A.; Bergman, H.; Burko, B.; Dagenais, E.; et al. Current Referral Practices for Diagnosis and Intervention for Children with Cerebral Palsy: A National Environmental Scan. J. Pediatr. 2020, 216, 173-180.e1. [CrossRef]

3. Khandaker, G.; Muhit, M.; Karim, T.; Smithers-Sheedy, H.; Novak, I.; Jones, C.; Badawi, N. Epidemiology of cerebral palsy in Bangladesh: A population-based surveillance study. Dev. Med. Child. Neurol. 2019, 61, 601-609. [CrossRef]

4. Novak, I.; Morgan, C.; Fahey, M.; Finch-Edmondson, M.; Galea, C.; Hines, A.; Langdon, K.; Namara, M.M.; Paton, M.C.B.; Popat, H.; et al. State of the Evidence Traffic Lights 2019: Systematic Review of Interventions for Preventing and Treating Children with Cerebral Palsy. Curr. Neurol. Neurosci. Rep. 2020, 20, 3. [CrossRef]

5. Kleim, J.A.; Jones, T.A. Principles of Experience-Dependent Neural Plasticity: Implications for Rehabilitation After Brain Damage. J. Speech. Lang. Hear. Res. 2008, 51, S225-S239. [CrossRef]

6. Byrne, R.; Noritz, G.; Maitre, N.L. Implementation of Early Diagnosis and Intervention Guidelines for Cerebral Palsy in a High-Risk Infant Follow-Up Clinic. Pediatr. Neurol. 2017, 76, 66-71. [CrossRef]

7. Maitre, N.L.; Burton, V.J.; Duncan, A.F.; Iyer, S.; Ostrander, B.; Winter, S.; Ayala, L.; Burkhardt, S.; Gerner, G.; Getachew, R.; et al. Network Implementation of Guideline for Early Detection Decreases Age at Cerebral Palsy Diagnosis. Pediatrics 2020, 145. [CrossRef]

8. Voress, J.K.; Maddox, T. Developmental Assessment of Young Children Second Edition (DAYC-2); Pro-Ed: Austin, TX, USA, 2013.

9. Nelson, K.B.; Ellenberg, J.H. Antecedents of Cerebral Palsy. N. Engl. J. Med. 1986, 315, 81-86. [CrossRef]

10. McIntyre, S.; Blair, E.; Badawi, N.; Keogh, J.; Nelson, K.B. Antecedents of cerebral palsy and perinatal death in term and late preterm singletons. Obs. Gynecol. 2013, 122, 869-877. [CrossRef]

11. Morgan, C.; Crowle, C.; Goyen, T.A.; Hardman, C.; Jackman, M.; Novak, I.; Badawi, N. Sensitivity and specificity of General Movements Assessment for diagnostic accuracy of detecting cerebral palsy early in an Australian context. J. Paediatr. Child. Health 2016, 52, 54-59. [CrossRef]

12. Proctor, E.K.; Powell, B.J.; McMillen, J.C. Implementation strategies: Recommendations for specifying and reporting. Implement. Sci. 2013, 8, 139. [CrossRef]

13. Goyen, T.-A.; Morgan, C.; Crowle, C.; Hardman, C.; Day, R.; Novak, I.; Badawi, N. Sensitivity and specificity of general movements assessment for detecting cerebral palsy in an Australian context: 2-year outcomes. J. Paediatr. Child. Health 2020, 56, 1414-1418. [CrossRef]

14. Pinnock, H.; Barwick, M.; Carpenter, C.R.; Eldridge, S.; Grandes, G.; Griffiths, C.J.; Rycroft-Malone, J.; Meissner, P.; Murray, E.; Patel, A.; et al. Standards for Reporting Implementation Studies (StaRI) Statement. BMJ 2017, 356. [CrossRef]

15. Baker, R.; Camosso-Stefinovic, J.; Gillies, C.; Shaw, E.J.; Cheater, F.; Flottorp, S.; Robertson, N. Tailored interventions to overcome identified barriers to change: Effects on professional practice and health care outcomes. Cochrane Database Syst. Rev. 2010, 3, Cd005470. [CrossRef]

16. Williams, S.A.; Mackey, A.; Sorhage, A.; Battin, M.; Wilson, N.; Spittle, A.; Stott, N.S. Clinical practice of health professionals working in early detection for infants with or at risk of cerebral palsy across New Zealand. J. Paediatr. Child. Health 2020, $541-547$. [CrossRef]

17. Lizarondo, L.; Grimmer-Somers, K.; Kumar, S. A systematic review of the individual determinants of research evidence use in allied health. J. Multidiscip. Healthc. 2011, 4, 261-272. [CrossRef] [PubMed]

18. Francke, A.L.; Smit, M.C.; de Veer, A.J.E.; Mistiaen, P. Factors influencing the implementation of clinical guidelines for health care professionals: A systematic meta-review. BMC Med. Inform. Decis. Mak. 2008, 8, 38. [CrossRef]

19. Flodgren, G.; Parmelli, E.; Doumit, G.; Gattellari, M.; O’Brien, M.A.; Grimshaw, J.; Eccles, M.P. Local opinion leaders: Effects on professional practice and health care outcomes. Cochrane Database Syst. Rev. 2011, 8, CD000125. [CrossRef] [PubMed]

20. Abdullah, G.; Rossy, D.; Ploeg, J.; Davies, B.; Higuchi, K.; Sikora, L.; Stacey, D. Measuring the Effectiveness of Mentoring as a Knowledge Translation Intervention for Implementing Empirical Evidence: A Systematic Review. Worldviews Evid. Based Nurs. 2014, 11, 284-300. [CrossRef] [PubMed]

21. Gagliardi, A.R.; Légaré, F.; Brouwers, M.C.; Webster, F.; Badley, E.; Straus, S. Patient-mediated knowledge translation (PKT) interventions for clinical encounters: A systematic review. Implement. Sci. 2016, 11, 26. [CrossRef]

22. Wenke, R.J.; Ward, E.C.; Hickman, I.; Hulcombe, J.; Phillips, R.; Mickan, S. Allied health research positions: A qualitative evaluation of their impact. (Report). Health Res. Policy Syst. 2017, 15. [CrossRef]

23. Harding, K.; Lynch, L.; Porter, J.; Taylor, N.F. Organisational benefits of a strong research culture in a health service: A systematic review. Aust. Health Rev. 2016, 41, 45-53. [CrossRef]

24. Graham, D.I.; Logan, B.J.; Harrison, E.M.; Straus, E.S.; Tetroe, E.J.; Caswell, E.W.; Robinson, E.N. Lost in knowledge translation: Time for a map? J. Contin. Educ. Health Prof. 2006, 26, 13-24. [CrossRef]

25. Hoffmann, T.C.; Glasziou, P.P.; Boutron, I.; Milne, R.; Perera, R.; Moher, D.; Altman, D.G.; Barbour, V.; Macdonald, H.; Johnston, M.; et al. Better reporting of interventions: Template for intervention description and replication (TIDieR) checklist and guide. BMJ 2014, 348, g1687. [CrossRef] [PubMed] 
26. Australian Bureau of Statistics National, State and Territory Population. Available online: https://www.abs.gov.au/statistics (accessed on 5 April 2021).

27. Solaski, M.; Majnemer, A.; Oskoui, M. Contribution of socio-economic status on the prevalence of cerebral palsy: A systematic search and review. Dev. Med. Child. Neurol. 2014, 56, 1043-1051. [CrossRef] [PubMed]

28. Einspieler, C.; Prechtl, H.F.R. Prechtl's assessment of general movements: A diagnostic tool for the functional assessment of the young nervous system. Ment. Retard. Dev. Disabil. Res. Rev. 2005, 11, 61-67. [CrossRef] [PubMed]

29. Boychuck, Z.; Andersen, J.; Bussieres, A.; Fehlings, D.; Kirton, A.; Li, P.; Oskoui, M.; Rodriguez, C.; Shevell, M.; Snider, L.; et al. International expert recommendations of clinical features to prompt referral for diagnostic assessment of cerebral palsy. Dev. Med. Child. Neurol. 2020, 62, 89-96. [CrossRef] [PubMed]

30. McIntyre, S.; Morgan, C.; Walker, K.; Novak, I. Cerebral palsy—Don't delay. Dev. Disabil Res. Rev. 2011, 17, 114-129. [CrossRef] [PubMed]

31. McIntyre, S.; Taitz, D.; Keogh, J.; Goldsmith, S.; Badawi, N.; Blair, E. A systematic review of risk factors for cerebral palsy in children born at term in developed countries. Dev. Med. Child. Neurol. 2013, 55, 499-508. [CrossRef]

32. Rosenbaum, P.; Paneth, N.; Leviton, A.; Goldstein, M.; Bax, M.; Damiano, D.; Dan, B.; Jacobsson, B. A report: The definition and classification of cerebral palsy April 2006. Dev. Med. Child. Neurol. Suppl. 2007, 109, 8-14.

33. King, S.; King, G.; Rosenbaum, P. Evaluating Health Service Delivery to Children with Chronic Conditions and Their Families: Development of a Refined Measure of Processes of Care (MPOC-20). Child. Health Care. 2004, 33, 35-57. [CrossRef]

34. Dobbins, T.A.; Sullivan, E.A.; Roberts, C.L.; Simpson, J.M. Australian national birthweight percentiles by sex. and gestational age, 1998-2007. Med. J. Aust. 2012, 197, 291-294. [CrossRef] [PubMed]

35. Romeo, D.M.; Cioni, M.; Palermo, F.; Cilauro, S.; Romeo, M.G. Neurological assessment in infants discharged from a neonatal intensive care unit. Eur. J. Paediatr. Neurol. 2013, 17, 192-198. [CrossRef] [PubMed]

36. Australian Cerebral Palsy Register Group. Report of the Australian Cerebral Palsy Register Birth Years 1995-2012; Australian Cerebral Palsy Register: North Adelaide, Australia, 2018.

37. Palisano, R.; Rosenbaum, P.; Walter, S.; Russell, D.; Wood, E.; Galuppi, B. Development and reliability of a system to classify gross motor function in children with cerebral palsy. Dev. Med. Child. Neurol. 1997, 39, 214-223. [CrossRef] [PubMed]

38. King, A.R.; Machipisa, C.; Finlayson, F.; Fahey, M.C.; Novak, I.; Malhotra, A. Early detection of cerebral palsy in high-risk infants: Translation of evidence into practice in an Australian hospital. J. Paediatr. Child. Health 2021, 57, 246-250. [CrossRef]

39. Crowle, C.; Badawi, N.; Walker, K.; Novak, I. General Movements Assessment of infants in the neonatal intensive care unit following surgery. J. Paediatr. Child. Health 2015, 51, 1007-1011. [CrossRef] [PubMed]

40. de Vries, L.S.; van Haastert, I.C.; Benders, M.J.N.L.; Groenendaal, F. Myth: Cerebral palsy cannot be predicted by neonatal brain imaging. Semin. Fetal Neonatal Med. 2011, 16, 279-287. [CrossRef]

41. Ibrahim, J.; Mir, I.; Chalak, L. Brain imaging in preterm infants $<32$ weeks gestation: A clinical review and algorithm for the use of cranial ultrasound and qualitative brain MRI. Pediatr. Res. 2018, 84, 799-806. [CrossRef] [PubMed]

42. Ashwal, S.; Russman, B.S.; Blasco, P.A.; Miller, G.; Sandler, A.; Shevell, M.; Stevenson, R. Practice Parameter: Diagnostic assessment of the child with cerebral palsy: Report of the Quality Standards Subcommittee of the American Academy of Neurology and the Practice Committee of the Child Neurology Society. Neurology 2004, 62, 851-863. [CrossRef]

43. Bax, M.; Tydeman, C.; Flodmark, O. Clinical and MRI correlates of cerebral palsy: The European Cerebral Palsy Study. JAMA 2006, 296, 1602-1608. [CrossRef]

44. Reid, S.M.; Dagia, C.D.; Ditchfield, M.R.; Carlin, J.B.; Reddihough, D.S. Population-based studies of brain imaging patterns in cerebral palsy. Dev. Med. Child. Neurol. 2014, 56, 222-232. [CrossRef]

45. Morgan, C.; Romeo, D.; Chorna, O.; Novak, I.; Galea, C.; Del Secco, S.; Guzzetta, A. The Pooled Diagnostic Accuracy of Neuroimaging, General Movements, and Neurological Examination for Diagnosing Cerebral Palsy Early in High-Risk Infants: A Case Control Study. J. Clin. Med. 2019, 8, 1879. [CrossRef]

46. Folio, M.; Fewell, R. Peabody Developmental Motor Scales, 2nd ed.; Pro-Ed: Austin, TX, USA, 2000.

47. Krumlinde-Sundholm, L.; Ek, L.; Sicola, E.; Sjöstrand, L.; Guzzetta, A.; Sgandurra, G.; Cioni, G.; Eliasson, A.C. Development of the Hand Assessment for Infants: Evidence of internal scale validity. Dev. Med. Child. Neurol. 2017, 59, 1276-1283. [CrossRef]

48. Byrne, R.; Duncan, A.; Pickar, T.; Burkhardt, S.; Boyd, R.N.; Neel, M.L.; Maitre, N.L. Comparing parent and provider priorities in discussions of early detection and intervention for infants with and at risk of cerebral palsy. Child. Care Health Dev. 2019, 45, 799-807. [CrossRef]

49. Williams, S.A.; Alzaher, W.; Mackey, A.; Hogan, A.; Battin, M.; Sorhage, A.; Stott, N.S. “It Should Have Been Given Sooner, and We Should Not Have to Fight for It": A Mixed-Methods Study of the Experience of Diagnosis and Early Management of Cerebral Palsy. J. Clin. Med. 2021, 10, 1398. [CrossRef]

50. Novak, I.; Morgan, C.; McNamara, L.; te Velde, A. Best practice guidelines for communicating to parents the diagnosis of disability. Early Hum. Dev. 2019, 139. [CrossRef]

51. Chen, A.; Dyck Holzinger, S.; Oskoui, M.; Shevell, M. Losing a diagnosis of cerebral palsy: A comparison of variables at 2 and 5 years. Dev. Med. Child. Neurol. 2020, 62, 83-88. [CrossRef] [PubMed]

52. Baird, G.; McConachie, H.; Scrutton, D. Parents' perceptions of disclosure of the diagnosis of cerebral palsy. Arch. Dis. Child. 2000, 83, 475-480. [CrossRef] 
53. Arnadottir, U.; Egilson, S.T. Evaluation of therapy services with the Measure of Processes of Care (MPOC-20): The perspectives of Icelandic parents of children with physical disability. J. Child. Health Care 2012, 16, 62-74. [CrossRef] [PubMed]

54. Cerebral Palsy Alliance Early Intervention Therapy: A Guide for Parents of Babies and Children aged 0-2 with Cerebral Palsy. Available online: https:/ / cerebralpalsy.org.au/services/all-programs-and-services/eci/\#eci-guide (accessed on 16 May 2021).

55. Marchi, V.; Hakala, A.; Knight, A.; D’Acunto, F.; Scattoni, M.L.; Guzzetta, A.; Vanhatalo, S. Automated pose estimation captures key aspects of General Movements at eight to 17 weeks from conventional videos. Acta Paediatr. 2019, 108, 1817-1824. [CrossRef] [PubMed]

56. Kanji, A.; Khoza-Shangase, K.; Moroe, N. Newborn hearing screening protocols and their outcomes: A systematic review. Int. J. Pediatr. Otorhinolaryngol. 2018, 115, 104-109. [CrossRef] [PubMed]

57. Vlastarakos, P.V.; Proikas, K.; Papacharalampous, G.; Exadaktylou, I.; Mochloulis, G.; Nikolopoulos, T.P. Cochlear implantation under the first year of age-The outcomes. A critical systematic review and meta-analysis. Int. J. Pediatr. Otorhinolaryngol. 2009, 74, 119-121. [CrossRef] [PubMed] 